hands and looking elsewhere for equipment, simply because we don't have the calibre of engineer to produce the sort of equipment they require.

Not surprisingly then, the study group is recommending that steps should be taken to see that British industry becomes acquainted with the meaning and value of the masters degree. Also they suggest a tightening up of the admission procedures to a $\mathrm{PhD}$ course, in view of justified criticism to the effect that less than ideal candidates are being accepted, and in some cases are receiving the degree. To weed out the stragglers before they have gone too far, the Vice-Chancellors will be asking universities to consider the introduction of a more formal and rigorous assessment of progress, possibly in the form of a written examination or preliminary dissertation, at the end of the first year of a PhD course. And by way of consolation for the candidates who get over this additional hurdle in the education race, there is a recommendation that a special mark of distinction might be considered for outstanding theses. So if all goes well it will only be a matter of time before the plushest jobs are reserved for thinkers with an upper second $\mathrm{PhD}$ or better.

Perhaps by way of a reply to Lord Crowther-Hunt, the report steered clear of making recommendations about the relation between student places and manpower requirements. Apart from areas like medicine and law, where there is a clear connection between the number of career openings and university places, the ViceChancellors suggest that in general, progress to postgraduate education should be on the principle that any student who is "qualified, suitable and keen to proceed" beyond first degree level should be able to do so.

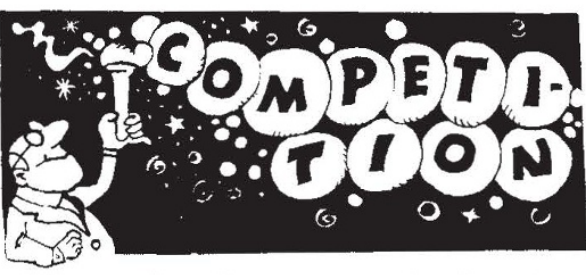

THis week we're running the first in a series of competitions designed to allow scientific minds a flight of literary fancy. Two or three weeks' leeway will be allowed for overseas entrants, but UK competitors are asked to submit their efforts within a week of publication. $£ 10$ is available for the best entry or entries.

No. 1: Dissident scientists in the Soviet Union are forced to confine their activities to the meetings of the famous Sunday seminars. A prize for the minutes (not more than 150 words) of an illicit seminar somewhere in the Western world.

\title{
correspondence
}

\section{Sulphones for leprosy}

Sir,-If Drs. Browne and Davey (Nature, May 15) agree with my statement (March 20) that "sulphones provide a cheap and practical form of treatment", why are most of the World's leprosy patients not receiving it? In countries or areas adopting the outpatient approach, the percentage on treatment is very high; for example, in an area of Northern Nigeria where I worked about $90 \%$; in a remote area of New Guinea $100 \%$ (Med. J. Anat., $1,1262,1971)$ and in an area of India, $60 \%$ after only three years of starting outpatient clinics (Dan. Med. Bull., 20, 198, 1973). In countries persisting with institutional care, such as Tanzania, only $33 \%$ receive treatment, and some patients have to travel up to 250 miles to receive it. Rehabilitation, including reconstructive surgery, prostheses, physiotherapy and occupational therapy, has greatly magnified the cost of institutional care. Vast sums have been spent on a rehabilitation centre (ALERT) in Ethiopia for crippled patients, yet only $40 \%$ of patients are receiving dapsone. Thus, it is the strategy employed which determines the number on treatment and not economic reasons or social aspects of the disease. Will Mr Van Den Wijngaert (May 22) tell us how much of the $£ 4$ million collected by the European anti-leprosy Association (ILEP) in 1973 was spent on institutional care, including rehabilitation, and how much on outpatient treatment?

The figures I quoted showing the rapid fall in leprosy incidence in areas where sulphones have been used, have been ignored by Drs. Browne and Davey. LEPRA have not published any incidence figures in their Malawi project, which started nine years ago, and ILEP have not used money for this purpose. Thus, it is a failure of evaluation, rather than a failure of sulphones to rapidly interrupt transmission, which is the problem. A proved and practicable method of prevention is available and no more time should be wasted on BCG or chemoprophylaxis. Immunoprophylaxis using dead M. leprae from infected armadillos, as suggested by Drs Browne and Davey, has no proven preventive effect.

If government are informed of these facts, if voluntary agencies spend the money on treating patients before they become crippled and if WHO arranges for proper evaluation, then all leprosy patients can be treated and the disease could probably be eradicated within the next ten years.

\section{Department of Anatomy and Embryology \\ University College London.}

\section{North to Alaska}

SIR,-In her correspondence "North to Alaska" (May 29) Angela Croome states that no ship got through the North
West passage until 1944. This is not quite correct. During the years 1903-06 the Norwegian explorer Roald Amundsen succeeded in getting his little ship Gjøa through. Thus he is rightly credited with the "discovery" of the North West passage.

Yours faithfully, K. Stenstadvold

University of Trondheim, Norway

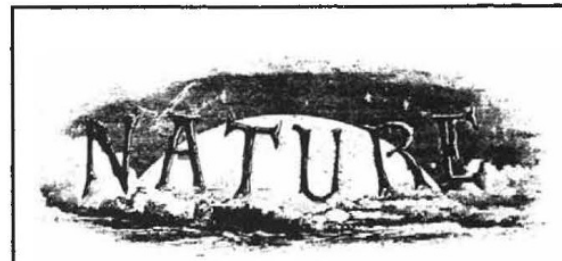

\section{A hundred years ago}

THE recent French inundations have recalled to memory an experiment which was tried twelve years ago before Napoleon III. The design was to manufacture mattresses of cork, so that any one on board a ship or in a house which could be flooded would have in his bed a ready-made raft capable of floating under a weight of more than $1 \mathrm{cwt}$. for any length of time. Cork is a material so soft that mattresses made of it are not inferior to any other for comfort.

from Nature, 12, 280; August 5, 1875. 